\title{
Factors influencing women's choice of health care provider during childbirth in Port Harcourt, Southern Nigeria
}

\author{
Terhemen Kasso*, Gregory W. Asuquo
}

Department of Obstetrics and Gynaecology, University of Port Harcourt Teaching Hospital, Port Harcourt, Nigeria

Received: 12 January 2022

Accepted: 02 February 2022

\author{
*Correspondence: \\ Dr. Terhemen Kasso, \\ E-mail: terhemen.kasso@uniport.edu.ng
}

Copyright: () the author(s), publisher and licensee Medip Academy. This is an open-access article distributed under the terms of the Creative Commons Attribution Non-Commercial License, which permits unrestricted non-commercial use, distribution, and reproduction in any medium, provided the original work is properly cited.

\begin{abstract}
Background: Maternal mortality is high in sub-Saharan African countries. Maternal deaths are preventable if births are attended by skilled health care providers who can manage complications promptly when they arise. Some women however patronise traditional birth attendants who contribute to maternal mortality in Nigeria due to their inability to manage complications during and after delivery. The aim of this study was to ascertain the factors influencing women's choice of healthcare provider during childbirth and their effect on maternal mortality in Port Harcourt, Rivers State, Nigeria.

Methods: A descriptive cross-sectional design was used to elicit information from mothers attending postnatal and immunization clinics at University of Port Harcourt Teaching Hospital. An interviewer-administered questionnaire was used to obtain information and the data collected was analysed using statistical package for social sciences (SPSS) version 22 and presented as frequencies and percentages in tables and charts.

Results: The study revealed that $90.5 \%$ of the respondent's identified obstetricians as the most skilled for delivery and most $(91.5 \%)$ had utilized their services. Majority (93.5\%) had good perception about obstetricians, $54.5 \%$ were not satisfied with the cost of their services stating that it was expensive. Some factors identified to influence delivery with TBAs were cheap services, ignorance, belief system, easy accessibility, availability and lesser time consumption. Conclusions: Cheap TBA services attracted women to their utilisation. Reduction in the cost of modern obstetric services will enhance their utilization, improve obstetric outcome and reduce maternal deaths.
\end{abstract}

Keywords: Maternal mortality, Skilled health care, TBAs

\section{INTRODUCTION}

Globally, despite a reduction in maternal mortality ratio from 385 per 100,000 live births to 216 per 100,000 live births between the years 1990 to 2015 , about 830 women still die each day due to complications of pregnancy and child birth. ${ }^{1}$ Majority of these deaths occur in developing countries with more than half occurring in sub-Saharan Africa and nearly one third occurring in south Asia. ${ }^{1}$ In the developed countries, there is a decline in maternal mortality ratio as a result of availability of modern health care facilities and skilled birth attendants during pregnancy and child birth. The choice of health care provider during childbirth affects maternal mortality ratio taking into consideration that some health care providers may lack the necessary skills and knowledge to conduct a safe delivery and manage complications that may arise during childbirth. In sub-Saharan African countries, several factors ranging from lack of access to modern health care services, choice of health care provider, poverty and cultural practices are some of the factors that prevent majority of the women from accessing skilled birth attendants during childbirth. ${ }^{1}$

A health care provider is defined as a person who helps in identifying, preventing or treating illnesses or disability 
or simply any individual, institution or agency that provides health services to health care consumers in the society. $^{2}$ Apart from skilled birth attendants which include obstetricians (doctors) and midwives, traditional birth attendants are also patronized during childbirth by some communities and have one way or the other contributed to an increased in maternal mortality from inability to treat preventable complications during child birth. According to world health organization (WHO), a traditional birth attendant (TBA) is any person who assists the mother during childbirth, whose skills are acquired through apprenticeship involving both observation and imitation. ${ }^{3}$ In Nigeria, about 40,000 women die yearly as a result of complications of pregnancy and childbirth, accounting for about $14 \%$ of the global maternal mortality rate with traditional birth attendants (TBAs) contributing to this increased rate. ${ }^{4}$ In Kenya, TBAs were observed to provide delivery services in most rural communities. ${ }^{5}$ Similarly, in some parts of Nigeria, over $70 \%$ of deliveries are conducted at home by TBAs or family members. ${ }^{6,7}$ How effective TBAs are in communities that have accepted them is a big question mark. In some developing countries, it was observed that TBAs are effective in improving maternal and new born health outcomes. ${ }^{8-10}$ However, their effectiveness was achieved by training them on how to manage complications following child birth. ${ }^{8}$ In some other occasions, even when they have been trained with basic midwifery skills, their inability to access requisites clean delivery tools further increased the risk for infections during childbirth. ${ }^{8}$ However, it was observed that the incidence of postpartum complications were reduced in communities where necessary materials and equipment were provided to traditional midwives. ${ }^{11,12}$ In Nigeria, patronizing Traditional Birth Attendants during childbirth over the years has continued to increase and thus contributing to the rise in maternal and perinatal deaths from preventable complications. ${ }^{13,14}$

\section{Aim}

The aim of current study was to ascertain the factors influencing women's choice of healthcare provider during child birth and their effect on maternal mortality.

\section{METHODS}

\section{Study design}

The study was a descriptive cross-sectional design that assessed the factors influencing women's choice of health care provider during child birth by women attending postnatal and immunization clinics in University of Port Harcourt teaching hospital, Rivers state, Nigeria.

\section{Sampling of participants}

The study was carried out in November, 2019 for two weeks. All the women who came to the post-natal and immunization clinics for the duration of the study were selected using convenient sampling method and were informed about the study, but only those who gave consent were recruited. The postnatal clinic holds from Mondays to Fridays while the immunization clinic holds on Mondays, Wednesdays and Fridays in a week. On the average, 150 women attend both clinics in one week. A total of 200 women participated in the study.

\section{Data collection}

A structured interviewer-administered questionnaire was designed after critical review of literatures. The questionnaire comprised of socio-demographic characteristics of the women, their perception about health care providers, reason for choice of health care provider, satisfaction with the chosen health care provider, and perceived factors that contribute to utilization of TBAs, individual verbal consent was obtained from the women on each clinic day after the aim of the study was explained to them. The questionnaires were then administered to the respondents by the researcher, assisted by residents and nurses. Issues pertaining to confidentiality, voluntariness in participation, withdrawal from the study at any point were also stressed. The data collected was analysed using statistical package for social sciences (SPSS) version 22. The inferential statistics were tested using Chi-square and all tests were considered statistically significant at $\mathrm{p}$ $<0.05$. The results were represented by simple statistical methods using simple frequencies and percentages in tables and charts.

\section{RESULTS}

\section{Demographic data}

Majority of the respondents $(61.0 \%)$ were between $25-34$ years, $95.5 \%$ were married, $42.0 \%$ were self-employed while $40.0 \%$ were civil servants. Also, $99.5 \%$ were Christians, while $70.5 \%$ had $0-2$ children. Most of them $(81.5 \%)$ had tertiary education while $18.0 \%$ had secondary education. Economically, $34.0 \%$ of their monthly incomes were above 50,000 naira while $33.5 \%$ were below 25,000 naira (Table 1).

\section{Knowledge about obstetricians and TBAS}

More than half of the respondents $(66.5 \%)$ knew about obstetricians and $85.0 \%$ knew their function. Also, $84.2 \%$ were aware that obstetricians prevent complications and most of them $(92.5 \%)$ believed that they can manage complications during childbirth. Majority (84\%) knew who a TBA is and $91.7 \%$ knew that complications could arise from giving birth with a TBA. Majority of the respondents $(81.0 \%)$ felt that TBAs should not be allowed to continue delivering women because they lack skills, sterile equipment and there is increased risk of maternal mortality with the TBAs. Also, $19.0 \%$ of the respondents felt TBAs should be allowed to continue 
delivering women because of their cheap services an easy accessibility.

\section{Utilization of TBAS and other types of birth attendants}

Majority of the respondents $(91.5 \%)$ had not been delivered by unskilled birth attendants while $8.5 \%$ had been delivered by unskilled birth attendants. Most of them $(64.7 \%)$ did not have complications while $35.3 \%$ had complications after utilizing unskilled birth attendants. Among those who had complications, $66.7 \%$ said TBAs could not treat the complications while $33.3 \%$ said they could. Most (63.4\%) of the women felt that TBAs are still utilized due to their cheap services

\section{Women's perception about health care providers (obstetricians)}

Majority (90.5\%) of the respondents said obstetricians are the most skilled for delivery and $84.5 \%$ said they were friendly. The overall perception about obstetricians was above average (93.5\%) as shown in (Table 2).

\section{Women's satisfaction with the services of health care providers}

Majority $(94.5 \%)$ of the respondents were unsatisfied with the approach of TBAs (Table 3). However, 66.5\% stated that their services were cheap. Also, 78.5\% said they spent less time with TBAs while $74.0 \%$ were not satisfied with the number of visits with the TBA. More than half of the respondents $(86.5 \%)$ were satisfied with obstetricians' approach. However, $54.5 \%$ of them felt their services are too expensive. Overall, most of the women $(59.0 \%)$ were satisfied with the number of visits.

\section{Identification of the women's choice of health care provider and their reasons}

Total $91.5 \%$ of the respondents preferred to use modern health facilities and their reasons were majorly due to reduced complications and good health outcome (Table 4). Majority of them $(98.5 \%)$ said it was not their belief to be delivered by unskilled birth attendants. However, $1.5 \%$ preferred TBA and $61.5 \%$ of those who preferred TBA registered in a hospital because of their husband's decision while $38.5 \%$ said it was for formality's sake.

\section{Perceived factors that contribute to the utilization of TBAS amongst women}

Majority of the respondents (99.0\%) stated that TBAs are cheap, $95.0 \%$ agreed that they are patronized out of ignorance, $86.0 \%$ agreed that they are user satisfying, $80.0 \%$ said they are accessible, $97.5 \%$ said they are patronized due to the women's belief, while $2.0 \%$ said they had no alternative (Table 5). More than half of the respondents $(88.0 \%)$ perceived modern health care services as time consuming, $50.0 \%$ said modern health facilities are scarce while $42 \%$ stated that poor attitude of other staff, especially nurses and midwives contributes to poor utilization of modern health care facilities.

Table 1: Socio-demographic characteristics of respondents $(n=200)$.

\begin{tabular}{|c|c|c|}
\hline Variables & $\mathbf{N}$ & $\%$ \\
\hline \multicolumn{3}{|l|}{ Age (years) } \\
\hline$<18$ & 0 & 0 \\
\hline $18-24$ & 21 & 10.5 \\
\hline $25-34$ & 122 & 61.0 \\
\hline $35-44$ & 56 & 28.0 \\
\hline$>44$ & 1 & 0.5 \\
\hline \multicolumn{3}{|l|}{ Occupation } \\
\hline Civil servant & 80 & 40.0 \\
\hline Trading & 17 & 8.5 \\
\hline Self employed & 84 & 42.0 \\
\hline Unemployed & 19 & 9.50 \\
\hline \multicolumn{3}{|l|}{ Ethnicity } \\
\hline Yoruba & 15 & 7.5 \\
\hline Hausa & 0 & 0.0 \\
\hline Igbo & 95 & 47.5 \\
\hline Others & 90 & 45.0 \\
\hline \multicolumn{3}{|l|}{ Religion } \\
\hline Christianity & 199 & 99.5 \\
\hline Islam & 0 & 0.0 \\
\hline Others & 1 & 0.5 \\
\hline \multicolumn{3}{|l|}{ Marital status } \\
\hline Single & 8 & 4.0 \\
\hline Married & 191 & 95.5 \\
\hline Divorced/separated & 1 & 0.5 \\
\hline \multicolumn{3}{|l|}{ Number of children } \\
\hline $0-2$ & 141 & 70.5 \\
\hline $3-5$ & 53 & 26.5 \\
\hline$>5$ & 6 & 3.0 \\
\hline \multicolumn{3}{|l|}{ Level of education } \\
\hline Primary & 1 & 0.50 \\
\hline Secondary & 36 & 18.0 \\
\hline Tertiary & 163 & 81.5 \\
\hline \multicolumn{3}{|c|}{ Monthly income (Naira) } \\
\hline$<25,000$ & 67 & 33.5 \\
\hline $25,000-50,000$ & 65 & 32.5 \\
\hline$>50,000$ & 68 & 34.0 \\
\hline
\end{tabular}

\section{DISCUSSION}

This study observed an influence of socio-demographic factors in predicting the choice of health care provider during childbirth by women in Port Harcourt and this observation is not different from what was found in previous studies which observed that socio-demographic factors could predict the place of delivery. ${ }^{15,16}$ In this study, majority of the women who utilized skilled birth attendants were of the younger age groups, educated, economically stable and had less number of children. These findings are similar to other previous studies which observed that high delivery rate in a health care facility 
was commoner amongst women that were highly educated, having low parity and with high family income. ${ }^{17,18-20}$

Table 2: Women's perception about health care providers $(\mathbf{n}=\mathbf{2 0 0})$.

\begin{tabular}{|c|c|c|}
\hline Perception & $\mathbf{N}$ & $\%$ \\
\hline \multicolumn{3}{|c|}{ Who is most skilled for childbirth? } \\
\hline Obstetricians & 181 & 90.5 \\
\hline TBAs & 13 & 6.5 \\
\hline $\begin{array}{l}\text { Church women and elderly } \\
\text { women in the family }\end{array}$ & 0 & 0 \\
\hline I do not know & 6 & 3.0 \\
\hline \multicolumn{3}{|c|}{$\begin{array}{l}\text { How do you see the attitude/approach of the } \\
\text { obstetricians? }\end{array}$} \\
\hline Friendly & 169 & 84.5 \\
\hline Unfriendly & 29 & 14.5 \\
\hline Don't know & 2 & 1.0 \\
\hline \multicolumn{3}{|c|}{$\begin{array}{l}\text { How do the obstetricians talk to you or other } \\
\text { women? }\end{array}$} \\
\hline Nicely & 149 & 74.5 \\
\hline Rude & 43 & 21.5 \\
\hline Don't know & 8 & 4.0 \\
\hline \multicolumn{3}{|l|}{ Perception category? } \\
\hline Poor $(<50 \%)$ & 13 & 6.5 \\
\hline Good $(>50 \%)$ & 187 & 93.5 \\
\hline
\end{tabular}

Also, other previous studies observed that older women with no formal education, low-income earners and women of high parity preferred home deliveries. ${ }^{21,22,16}$ This could be explained on the basis that women with low education may be ignorant and those with low source of income may not be able to pay for the services of skilled birth attendants (SBAs) which are usually too expensive while those with high parity may be too confident of themselves due to previous successful deliveries outside a modern health care facility. Contrary to these findings, other previous studies observed that older women preferred modern health care facility during childbirth and this was as a result of fear of complications. ${ }^{23,17}$ In this study, most of the respondents knew who an obstetrician was and their function. Also, majority of them believed that delivering their babies by an obstetrician would have fewer complications. In addition, majority knew about traditional birth attendants and their function and most of them agreed that delivering in the place of TBA could lead to serious complications. These findings are not farfetched as many of the respondents were educated. In this study, majority of the women felt TBAs should not be allowed to continue taking deliveries in Nigeria due to complications from lack of skills and sterile equipment. This finding is similar to previous studies which observed that delivering in the place of a TBA could lead to serious complications as a result of lack of sterile equipment and their inabilities to manage complications during and after delivery. ${ }^{23-25}$

Table 3: Women's satisfaction with the services of health care providers.

\begin{tabular}{|lllll|}
\hline Satisfaction with & Obstetrician & & TBA's & Yes (\%) \\
\hline Approach & Yes (\%) & No (\%) & No) \\
\hline Attitude & $173(86.5)$ & $27(13.5)$ & $11(5.5)$ & $189(94.5)$ \\
\hline Communication & $164(82.0)$ & $36(18.0)$ & $56(28.0)$ & $144(72.0)$ \\
\hline Cost of services & $161(80.5)$ & $39(19.5)$ & $14(7.0)$ & $186(93.0)$ \\
\hline Shorter time spent & $91(45.5)$ & $109(54.5)$ & $133(66.5)$ & $67(33.5)$ \\
\hline Number of visits & $58(29.0)$ & $142(71.0)$ & $157(78.5)$ & $43(21.5)$ \\
\hline
\end{tabular}

Some of the women in this study felt TBAs should be allowed to continue taking delivery due to cheap services and easy accessibility.

This finding is similar to previous studies which observed that most of the women who patronized unskilled birth attendants were as a result of cheap services and easy accessibility when compared to modern health care facilities that were difficult to access due to distance and high cost of services. ${ }^{14,26}$

In this study, the women mentioned infection, bleeding, obstructed labour and convulsion as complications that could arise from delivering with a TBA. Similar observations were noted in previous studies that reported obstetric haemorrhage, eclampsia, sepsis, obstructed labour and complications of unsafe abortion as leading causes of maternal death in Nigeria. ${ }^{27,28}$ Findings from this study showed that only few of the women had utilized the services of an unskilled birth attendant and the major reason stated was cheap services. Moreover, most of them who utilized TBAs in the past had complications which could not be treated by TBAs. This limitation was similar to what was reported in a previous study which stated that majority of the participants recognized that TBAs lacked the competence in managing obstetric complications during childbirth due to their inabilities to effectively treat complications that occurred from their previous deliveries with TBAs. ${ }^{29}$

Generally, it was noted from this study that majority of the women had good perception about obstetricians in terms of attitude, methods of communication and pattern of care offered during delivery. These reasons could account for the high utilization of obstetricians by the women in this study. 
Table 4: Identification of choice of health care provider by women and their reasons.

\begin{tabular}{|c|c|c|}
\hline Variables & $\mathbf{N}$ & $\%$ \\
\hline \multicolumn{3}{|c|}{ Which health care provider do you prefer? } \\
\hline TBA & 13 & 6.5 \\
\hline Modern health care & 183 & 91.5 \\
\hline Don't know & 4 & 2.0 \\
\hline \multicolumn{3}{|c|}{$\begin{array}{l}\text { What is the reason for your chosen health care } \\
\text { provider? }\end{array}$} \\
\hline $\begin{array}{l}\text { No complications/good health } \\
\text { outcome }\end{array}$ & 183 & 91.5 \\
\hline Due to distance & 7 & 3.5 \\
\hline Due to financial reasons & 6 & 3.0 \\
\hline Don't know & 4 & 2.0 \\
\hline \multicolumn{3}{|c|}{$\begin{array}{l}\text { Is it your belief/culture to be delivered by TBA or } \\
\text { experienced elderly women/relatives? }\end{array}$} \\
\hline Yes & 3 & 1.5 \\
\hline No & 197 & 98.5 \\
\hline \multicolumn{3}{|c|}{$\begin{array}{l}\text { If you prefer TBA, why did you register in the } \\
\text { hospital? } N=13\end{array}$} \\
\hline Because of husband's decision & 8 & 61.5 \\
\hline For formality sake & 5 & 38.5 \\
\hline Don't know & 0 & 0.0 \\
\hline
\end{tabular}

Table 5: Perceived factors that contribute to the utilization of TBAs amongst women.

\begin{tabular}{|lll|}
\hline $\begin{array}{l}\text { Reasons for } \\
\text { delivering with } \\
\text { TBA's or experienced } \\
\text { women/relatives }\end{array}$ & Yes $(\%)$ & No (\%) \\
\hline $\begin{array}{l}\text { They satisfy the } \\
\text { pregnant women }\end{array}$ & $172(86)$ & $28(14.0)$ \\
\hline They are cheap & $198(99)$ & $2(1.0)$ \\
\hline $\begin{array}{l}\text { The pregnant women } \\
\text { are ignorant }\end{array}$ & $190(95)$ & $10(5.0)$ \\
\hline $\begin{array}{l}\text { The pregnant women } \\
\text { have no alternative }\end{array}$ & $4(2.0)$ & $196(98.0)$ \\
\hline $\begin{array}{l}\text { TBA's are readily } \\
\text { accessible }\end{array}$ & $160(80)$ & $40(20.0)$ \\
\hline $\begin{array}{l}\text { The women belief in } \\
\text { TBAs }\end{array}$ & $195(97.5)$ & $5(2.5)$ \\
\hline $\begin{array}{l}\text { Because modern } \\
\text { health care services } \\
\text { are time consuming }\end{array}$ & $176(88)$ & $24(12.0)$ \\
\hline $\begin{array}{l}\text { Because modern } \\
\text { health care services } \\
\text { are scarce }\end{array}$ & $100(50)$ & $100(50.0)$ \\
\hline $\begin{array}{l}\text { Others (poor attitude } \\
\text { of nurses/midwives) }\end{array}$ & $84(42)$ & $116(58)$ \\
\hline
\end{tabular}

Comparing the services of obstetricians and TBAs based on women's satisfaction, it was noted that more than half of the women were not satisfied with the approach of TBAs; stating further that their attitude and methods of communication were poor. However, majority stated that their services are cheap and they spend less time with them. These findings were contrary to what was found in previous studies that observed a high utilization of TBAs due to satisfaction in terms of approach, attitude and communication methods. ${ }^{26,27}$ The same study further stated that the services of TBAs were cheap and affordable. This observed difference could be due to the fact that majority of the women in this study were educated and preferred to use modern health care facilities. With regards to satisfaction in this study, even though majority of the women were satisfied with obstetricians, they felt that their services were too expensive and time consuming.

These findings agreed with previous studies which observed that the high cost of services of skilled birth attendants reduced utilization by pregnant women during childbirth especially women with low income. ${ }^{18,27,29}$

In this study, the women preferred using modern health facilities during childbirth, with most of them stating good health outcome and fewer complications as reasons. Almost all the women stated that it is not their belief to be delivered by an unskilled birth attendant (TBA) and these findings agreed with what was found in Ibadan and contrasts another previous study where it was notedthat religion and traditional belief in TBA determined women's utilization of modern health facilities and skilled birth attendants. ${ }^{27,30}$

With regards to women who preferred TBAs, it was noted that their husband's decision was the reason for registering for antenatal care and delivering in modern health care facilities. This observation is not surprising because in Africa, especially in Nigeria, men are usually the decision makers in the family. These findings are similar to previous studies done in rural Sierra Leone and Enugu Southern Nigeria which observed that men were the primary decision makers in deciding the place of childbirth in an average African family. ${ }^{30,31}$

The factors perceived as contributing to the utilization of TBAs amongst women in this study were cheap services, ignorance, belief for TBAs, poor accessibility, availability of modern health facilities and too much time consumption. These factors were also observed in other studies..$^{27,31-33}$ Some of the respondents further stated that staff, especially midwives/nurses discourage women from utilizing modern health facilities due to poor attitude. This observation was similar to what was observed in Ibadan and other previous studies. ${ }^{27,15,16}$

There was a statistically significant relationship between the women's income, education and their choice of health care provider. Those who were more educated and with higher income were more likely to utilise modern health care facilities.

This finding was contrary to a study in Ibadan that did not find a relationship between income of women and their choice of health care provider. ${ }^{27}$ 
Table 6: Relationship between income of women and their choice of healthcare provider.

\begin{tabular}{|lllllll|}
\hline Monthly income & TBA & Modern health & Total & Chi-square & P value & Remark \\
\cline { 1 - 4 } $\mathbf{2 5 0 0 0}$ & $13(4.355)$ & $54(61.3)$ & $67(18.031)$ & & & \\
\cline { 1 - 4 } $\mathbf{2 5 0 0 0 - 5 0 0 0 0}$ & $0(4.225)$ & $65(59.475)$ & $65(4.74)$ & & \multirow{2}{*}{24.00} & Significant \\
\cline { 1 - 4 } & $0(4.42)$ & $64(62.22)$ & $68(4.471)$ & & & \\
\hline
\end{tabular}

Table 7: Relationship between level of education of women and their choice of healthcare provider.

\begin{tabular}{|lllllll|}
\hline Education & TBA & Modern health & Total & Chi-square & P value & Remark \\
\cline { 1 - 4 } Primary & $1(0.1)$ & $0(0.9)$ & $1(9)$ & & & \\
\cline { 1 - 4 } Secondary & $12(2.3)$ & $24(32.9)$ & $36(43.316)$ & & \\
\cline { 1 - 6 } Tertiary & $0(10.6)$ & $159(149.1)$ & $159(4.471)$ & & & Significant \\
\hline
\end{tabular}

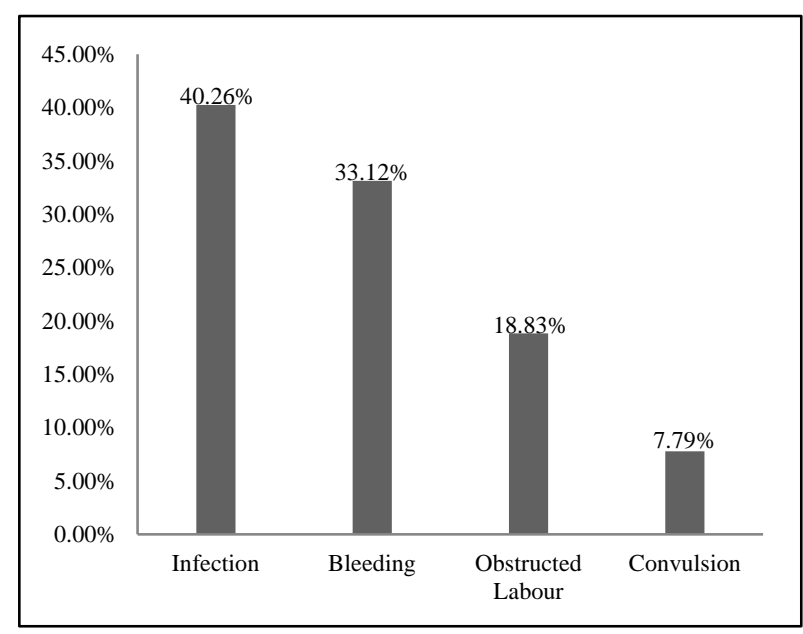

Figure 1: Complications that respondents think could occur when women deliver in a TBA's place.

This study has shown that majority of the women in Port Harcourt prefer to be delivered by skilled birth attendants. However, they felt that the services in modern health facilities were too expensive compared to those of traditional birth attendants. Also, the women had good perception about obstetricians describing them as doctors with good attitude, caring, with a friendly disposition. Community education alongside reduction in the cost of services in modern health care facilities will enhance utilization of modern obstetric services, improve obstetric outcome and reduce maternal mortality.

\section{ACKNOWLEDGEMENTS}

Authors would like to thank the resident doctors and nurses that assisted in the data collection and the staff of immunisation clinic of the University of Port Harcourt Teaching Hospital

\section{Funding: No funding sources}

Conflict of interest: None declared

Ethical approval: The study was approved by the Institutional Ethics Committee

\section{REFERENCES}

1. Trends in maternal mortality: 1990-2015: estimates from WHO, UNICEF, UNFPA, World Bank Group v and the United Nations Population Division. Available at: https://www.unfpa.org/publications/ trends-maternal-mortality-1990-2015. Accessed on 20 December 2021.

2. Mosby. Mosby's Medical Dictionary. United State of America: Elsevier; 2016.

3. Traditional birth attendants: a joint WHO/UNIFPA/UNICEF statement. Available at: http://www.who.int/iris/handle/10665/38994. Accessed on 20 December 2021.

4. Frederick W, ChimaraokeI Z. Maternal health in Nigeria: facts and figures. Available at: www.aphrc.org. Accessed on 20 December 2021.

5. Kaingu CK, Oduma JA, Kanui TI. Practices of traditional birth attendants in Machakos District, Kenya. J Ethnopharmacol. 2011;137(1):495-502.

6. Fapohunda BM, Orobaton NG. When women deliver with no one present in Nigeria: Who, What, Where and So What? Plos One. 2013;8(7):e69569.

7. Doctor HV, Findley SE, Ager A, Cometto G, Afenyadu GY, Adamu F, Green C. Using community - based research to shape the design and delivery of maternal health services in Northern Nigeria. Reprod Health Matters. 2012;20(39):104-12.

8. Gill CJ, Phiri-Mazala G, Guerina NG, Kasimba J, Mulenga C, Macleod WB, et al. Effects of training traditional birth attendants on neonatal mortality (Lufwanyama Neonatal Survival Project): randomised controlled study. BMJ. 2011;342:d346.

9. Miller PC, Rashida G, Tasneem Z. The effect of traditional birth attendant training on maternal and neonatal care. Int J Gynecol Obstet. 2012;117(2):14852.

10. Nyamtema AS, Urassa DP, Van Roosmalen J. Maternal health interventions in resource limited countries: a systematic review of packages, impacts and factors for change. BMC Pregnan Childbirth. 2011;11(1):1-2. 
11. Guerts KL. Well Being and birth in rural ghana: local realities and global mandates. Ann Penn Afr J. 1997; 17:131-54.

12. Bailey PE, Szaszdi JA, Glover L. Obstetric complications: does training traditional birth attendants make a difference? Revista Panamericana de Salud Publica. 2002;11(1):15.

13. Erim DO, Kolapo UM, Resch SC.A rapid assessment of the availability and use of obstetric care in Nigeria health care facilities. Plos One. 2012;7(6):e39555.

14. Oshonwoh FE, Nwakwuo GC, Ekiyor CD. Traditional birth attendants and women's health practices: A case study of Patani in southern Nigeria. J Public Health Epidemiol. 2014;6(8):252-61.

15. NgowiAF, Kamazima SR, Kibusi S, Gesase A, Bali T. Women's determinant factors for preferred place of delivery in Dodoma region Tanzania: a cross sectional study. Reprod Health. 2017;14(1):112-6.

16. Ashimi AO, Amole TG. Prevalence, reasons and predictors for home births among pregnant women attending antenatal care in Birnin Kudu, North- West Nigeria. Sexual Reprod Health Care. 2015;6(3):11925.

17. Bhattacharyya S, Srivastava A, Roy R, Avan B1. Factors influencing women's preference for health facility deliveries In Jharkhand state, India: a cross sectional analysis. BMC Pregnan Childbirth. 2016; 16(1):1-9.

18. Karanja S, Gichuki R, Igunza P, Muhula S, Ofware P, Lesiamon $\mathrm{J}$, et al. Factors influencing deliveries at health facilities in a rural maasai community in magadi Sub-country, Kenya. BMC Pregnan Childbirth. 2018;18(1):5-11.

19. Boah M, Mahama AB, Ayamga EA. They receive antenatal care in health facilities, yet do not deliver there: predictors of health facility delivery by women in rural Ghana. BMC Pregnan Childbirth. 2018; 18(1):125-29.

20. Dhakal P, Shrestha M, Baral D, Pathak S. Factors affecting the place of delivery among mothers residing in Jhorahat VDC, Morang Nepal. Int J Commu Based Nurs Midwifery. 2018;6 (1):2-11.

21. Shehu CE, Ibrahim MT, Oche MO, Nwobodo EI. Determinants of place of delivery: a comparison between an urban and a rural community in Nigeria. $\mathbf{J}$ Public Health Epidemiol. 2016;8(6):91-101.

22. Envuladu EA, Agbo HA, Lassa S, Kigbu JH, Zoakah AI. Factors determining the choice of a place of delivery among pregnant women in Russia village of Jos North, Nigeria: achieving the MDGs 4 and 5. Int J Med Biomed Res. 2013;2(1):23-7.

23. Gabrysch S, Campbell OM. Still too far to walk: literature review of the determinants of delivery services use. BMC Pregnan Childbirth. 2009;9(1):347.
24. Shambe IH, Pam VC, Enokela MA, Oyebode TA, Gyanga MD, Gryang BZ, et al. Reasons for choice of place of delivery among women of reproductive age in a semi urban population in north central Nigeria. J Biomed Res Clin Prac. 2018;1(1):61-6.

25. Shifraw T, Berhane Y, Gulema H, Kendall T, Austin A. A qualitative study on factors that influence women's choice of delivery in health facilities in Addis Ababa, Ethiopia. BMC pregnancy and childbirth. 2016;7(1):6-13.

26. Ogunyomi MT, Ndikom CM. Perceived factors influencing the utilization of Traditional Birth Attendant services in Akinyele Local government, Ibadan, Nigeria. J Commu Med Prim Health Care. 2016;28(2):40-8.

27. Ndikom CM, Ojoye TO, Nkworita CA. Factors influencing the choice of health care provider during childbirth by women in Ibadan, Oyo state, Nigeria. Int J Caring Sci. 2017;10 (1):511-21.

28. Oyeneyin LO, Akintan AL, Aderoba AK, Owa OO. Maternal mortality ratio in a tertiary hospital offering free maternity services in south western Nigeria - A five year review. Trop J Obstet Gynaecol. 2017;34: 112-5.

29. Caulfield T, Onyo P, Bryne A, Nduba J, Nyagero J, Morgan A, et al. Factors influencing place of delivery for pastoralist women in Kenya: a qualitative study. BMC women's Health. 2016;16(1):1-11.

30. Treacy L, Bolkan HA, Sagbakken M. Distance, accessibility and costs. Decision - making during childbirth in rural Sierra Leone: A qualitative study. Plos one. 2018;13(2): e0188280.

31. Ibekwe RO, Aniwada EC, Okpoko CC. Evaluating the socio-demographic predictors of choice of place of birth among women in the rural community in Enugu state, Nigeria. Asian J Pregnan Childbirth. 2018;1(1):1-8.

32. Ugboaja JO, Oguejiofor CB, Oranu EO, Igwegbe AO. Factors associated with the use of traditional birth attendants in Nigeria: A secondary analysis of 2013 Nigeria national demography and health survey. Niger J Gen Pract. 2018;16:45-52.

33. Yaya S, Bishwajit G, Uthman OA, Amouzou A. Why some women fail to give birth at health facilities: A comparative study between Ethiopia and Nigeria. Plos one. 2018;13(5):e0196896.

Cite this article as: Kasso T, Asuquo GW. Factors influencing women's choice of health care provider during childbirth in Port Harcourt, Southern Nigeria. Int J Reprod Contracept Obstet Gynecol 2022:11:689-95. 